Gut, 1986, 27, 778-783

Alimentary tract and pancreas

\title{
Short term treatment of gastric ulcer: a comparison of sucralfate and cimetidine
}

\author{
B HALLERBÄCK, O ANKER-HANSEN, L CARLING, H GLISE, \\ J-H SOLHAUG, L-E SVEDBERG, AND L WÄHLBY
}

From the Departments of Medicine and Surgery: Hospitals of Vänersborg, Bollnäs, Motala, Skövde and Torsby, Sweden

SUMMARY A double blind randomised study was undertaken to compare sucralfate and cimetidine in short term treatment of gastric ulcer. The study included 149 patients with endoscopically confirmed gastric ulcerations. Patients with prepyloric ulcers $2 \mathrm{~cm}$ or less from the pyloric ring were not accepted for participation in the trial. Ulcer healing was assessed endoscopically at four week intervals. A total of 134 patients completed the study. The cumulative healing rates after 12 weeks were $98 \%$ for sucralfate and $94 \%$ for cimetidine treated patients. After four and eight weeks, the healing rates were $61 \%$ and $94 \%$ for sucralfate and $69 \%$ and $94 \%$ for the cimetidine-treated group respectively. No statistically significant differences in healing rates were seen. The $95 \%$ confidence interval was calculated for the difference between the ulcer healing rates of sucralfate and cimetidine. This interval was found to range between $+11 \%$ and $-2 \%$ after 12 weeks of treatment - that is, the healing efficacy of sucralfate was calculated to be at most $11 \%$ better or $2 \%$ worse than that of cimetidine. No significant differences in symptom relief, side effects or antacid intake were found.

Peptic ulcer treatment has for many years been concentrated on reduction of intraluminal acidity. The efficacy of antacid agents in the treatment of gastric ulcer is, however, uncertain. ${ }^{1}$ Cimetidine, an $\mathrm{H}_{2}$-receptor antagonist with high acid reducing capacity, has recently been demonstrated in a few controlled studies to have a statistically better healing efficacy in gastric ulcer than placebo. ${ }^{2} 3$

The development of agents acting on the gastric mucosal barrier level, and having cytoprotective properties has provided a new method of combating peptic ulcer disease.

Sucralfate, a basic aluminium salt of sucrose octasulphate, is one of the new cytoprotective

Participating members of the Swedish group for Clinical Ulcer Research: Carling L, Svedberg L-E, Dept of Med, Bollnäs Hospital, Englund NE. Wadström S. Dept of Surg and Med. Borås Hospital. Lundberg K. Persson B Dept of Surg, Hudiksvall Hospital, Martinson J, Ohlin B. Dept of Surg,

Karlskrona Hospital. Axelsson J. Dept of Surg. Kristianstad Hospital, Carlsson S, Engström G. Hallgren T, Dept of Surg, Kungälv Hospital, Bergman B. Grimås Ö. Dept of Surg Ludvika Hospital, Anker-Hansen O. Dept of Surg. Motala Hospital, Karlander KE, Dept of Surg. Norrköping Hospital. Wählby L. Dept of Surg. Kärnsjukhuset. Skövde, Lindström C. Rågberg A. Sönne B. Dept of Surg. Söderhamn Hospital, Hallgren T, Solhaug JH. Dept of Surg. Torsby Hospital. Glise H (chief coordinator). Hallerbäck B. (coordinator), Jensen N. Pahlin P-E, Strid K. Dept of Surg, VänersborgTrollhättan Hospital, Hultén S, Stubberöd A. Ståhl L, Dept of Med and Surg, Värnamo Hospital. Hagenfeldt I. Åkesson H. Dept of Surg. Ångelholm Hospital, Lindberg E, Dept of Med, Örebro Hospital.

Address for correspondence: Hans Glise. Kir Klin Centrallasarettet. Fack 760. S-462 01 Vänersborg. Sweden.

Received for publication 11 October 1985. agents and has in previous studies given healing rates comparable with those given by cimetidine in the treatment of both duodenal and gastric ulcer. ${ }^{4-7}$

The main purpose of this study was to compare the healing rates and symptom relief in patients with acute gastric ulcer treated with sucralfate and cimetidine. The study was planned to include a sufficient number of patients to allow the calculation of a short $95 \%$ confidence interval for the difference in healing rates.

\section{Methods}

PATIENTS

The investigation was as a multicentre, double blind, randomised prospective study with the double dummy technique. Twenty two Swedish hospitals participated in the study. Each hospital should contribute with a minimum of five patients. The study was approved by the ethical committee of the University of Gothenburg and by the Swedish National Board of Health and Welfare.

\section{INCLUSION CRITERIA}

Patients aged 18 to 70 years with an endoscopically confirmed gastric ulcer were included in the study. Non-bleeding as well as bleeding ulcers were accepted. The minimum ulcer size diameter was $2 \mathrm{~mm}$. Prepyloric ulcers in a position $2 \mathrm{~cm}$ or less 
from the pyloric ring were not included. All ulcers were biopsied to exclude malignancy.

EXCLUSION CRITERIA

Chronic renal or hepatic disease, known malignancy, pregnancy, and lactation disqualified candidates inclusion. Patients with previous gastric resection or vagotomy or with coexistent duodenal and/or prepyloric ulcers were also excluded, as were patients on continuous medication with anti-inflammatory or anticoagulant drugs. Patients who had received antiulcer medication for more than seven days during the last four weeks before diagnosis were not accepted. Psychiatric disease or alcoholism making the patient incapable of cooperating also led to exclusion.

\section{ENDOSCOPY}

At inclusion, endoscopy was carried out and the ulcer size and location were noted. The ulcer size was estimated with a measuring probe or open biopsy forceps. At repeat endoscopy, the ulcer was considered to be healed if the ulcer site was totally epithelialised.

\section{TREATMEN T}

Patients taking part in the study which was in accordance with a preproduced code list randomly allocated to treatment with either sucralfate (Andapsin ${ }^{\circledR}$ Farmos Group AB) $1 \mathrm{~g}$ qid or cimetidine (Tagamet ${ }^{\circledR}$ SK\&F) $400 \mathrm{mg}$ bd. The maximum delay from endoscopy to start of treatment was five days. The patients received active tablets and dummies packed in plastic blisters daily. They were also given written and verbal instructions to take the sucralfate tablets one half to one hour before meals and not together with antacid tablets. Cimetidine tablets were to be taken together with meals and at bedtime, and not together with antacid tablets. The patients received 30 antacid tablets (Novalucol ${ }^{\circledR}$ Hässle, acid neutralizing capacity $12,5 \mathrm{mmol} /$ tablet) and were instructed to take the tablets only in situations of acute epigastric pain or heartburn. They were given more antacid tablets on request. The patients were also recommended to reduce their consumption of tobacco and coffee.

REGISTRATION OF SYMPTOMS, TABIET INTAKE AND SIDE EFFECTS

Current symptoms such as epigastric pain, heartburn, nausea and ulcer hemorrhage were recorded. During the trial, the patients recorded diurnal and nocturnal epigastric pain and heartburn on a special diary card. Missed tablets, antacid intake and daily consumption of tobacco and coffee were also recorded on the diary card. Unexpected symptoms during the study were also recorded by the patient.
FOLLOW UP AND CONTROLS

Each patient had a second contact with the investigator after 14 days, either by telephone or by personal visit. Repeat endoscopy was done after four weeks. If the ulcer was not healed the treatment was continued for another four week period. The maximum duration of treatment was 12 weeks.

\section{LABORATORY TESTS}

Laboratory tests were performed at inclusion and at the assessments after four, eight, and 12 weeks of treatment. The tests included haemoglobin, white blood cell count, platelets, creatinine, bilirubin, alkaline phosphatase (ALP), asparate aminotransferase (ASAT), and alanine aminotransferase (ALAT). The serum phosphate concentration was monitored in 54 patients.

\section{STATISTICAL METHODS}

The treatment groups were compared with respect to the variables recorded at entry to the study by means of Fisher's permutation test. ${ }^{8}$ If the groups were found initially to differ significantly with respect to any variable correlated to ulcer healing, special statistical measures were to be taken to correct for the differing variable in the main comparison of ulcer healing. Mantel's test ${ }^{9}$ was then to be used for analysis of the correlation between the entry variable and healing. The Mantel technique in this case means that the correlation between a variable and ulcer healing is first analysed within the sucralfate group and the cimetidine group separately and the results of the two groups are then pooled into one test. A two-sided interval for the difference in healing rates was to be calculated with $95 \%$ confidence limits. ${ }^{10}$ On the last day of each week during follow up, Fisher's exact test was used to compare the proportions of patients with epigastralgia. Similar comparisons were made for antacid intake and heartburn.

\section{Results}

PATIENT CHARACTERISTICS

Initially, 160 patients were included in the trial. Seven of the participating clinics did not reach the minimum limit of five patients and for this reason 10 patients were blindly excluded from the final evaluation. Another patient was over 70 years old and was also blindly excluded. Of the remaining 149 patients 75 were given sucralfate and 74 cimetidine. Gastric carcinoma was found in four patients in the sucralfate group and six patients in the cimetidine group. Control endoscopy was refused by two patients in each group. One patient in the sucralfate group had profuse ulcer bleeding which led to acute operation 
two days after the initial endoscopy. Of the 134 patients who completed the trial, 68 were treated with sucralfate and 66 with cimetidine (Table 1). The patient characteristics are shown in Table 2. A significant difference in mean ulcer size between the groups was found: $7.9 \mathrm{~mm}$ in the sucralfate group and $12.6 \mathrm{~mm}$ in the cimetidine group $(p<0.001)$. The distribution of ulcer size in the two groups is shown in Table 3 . Smoking habits also

Table 1 Causes of withdrawal among 149 gastric ulcer patients treated with sucralfate (1 g qid) or cimetidine (400 mg bd).

\begin{tabular}{lccc}
\hline & Sucralfate & Cimetidine & Total \\
\hline No & 75 & 74 & 149 \\
Gastric carcinoma & 4 & 6 & 10 \\
Refused control endoscopy & 2 & 2 & 4 \\
Blecding & 1 & & 1 \\
Remain in study & 68 & 66 & 134 \\
\hline
\end{tabular}

Table 2 Comparison of patient characteristics at entry to the study between 68 gastric ulcer patients treated with sucralfate ( $1 \mathrm{~g}$ qid) and 66 treated with cimetidine (400 $\mathrm{mg} \mathrm{bd}$ ).

\begin{tabular}{|c|c|c|c|}
\hline & Sucralfate & Cimetidine & \\
\hline No & 68 & 66 & \\
\hline Mean age (years) $\pm S D$ & $54 \pm 11 \cdot 9$ & $56 \cdot 5 \pm 9 \cdot 7$ & $\mathrm{~ns}$ \\
\hline Sex: males/females & $35 / 33$ & $32 / 34$ & ns \\
\hline Smokers & $32(47 \%)$ & $45(68 \%)$ & $\mathrm{p}<() \cdot(05$ \\
\hline Patients taking NSAID" & $16(23 \%)$ & $22(33 \%)$ & ns \\
\hline Patients drinking alcohol & $43(63 \%)$ & $44(67 \%)$ & $\mathrm{ns}$ \\
\hline Patients drinking coffee & $54(79 \%)$ & $58(88 \%)$ & ns \\
\hline \multicolumn{4}{|l|}{ Ulcer history: } \\
\hline Patients with first episode & $30(44 \%)$ & $32(48 \%)$ & ns \\
\hline Patients with relapse & $38(56 \%)$ & $34(52 \%)$ & ns \\
\hline \multicolumn{4}{|c|}{ Duration of current symptoms } \\
\hline$($ weeks $) \pm \mathrm{SD}$ & $8 \cdot 5 \pm 10 \cdot 5$ & $8 \cdot 2 \pm 8 \cdot 9$ & ns \\
\hline \multicolumn{4}{|l|}{ Duration of ulcer disease } \\
\hline Latest ulcer (years) $\pm S D$ & $4 \pm 7 \cdot 5$ & $3 \cdot 2 \pm 6 \cdot 3$ & ns \\
\hline \multicolumn{3}{|l|}{ Size of current ulcer } & $\mathrm{p}<() \cdot()(0) 1$ \\
\hline \multicolumn{4}{|c|}{ Patients with more than onc } \\
\hline ulcer & $12(18 \%)$ & $11(17 \%)$ & $\mathrm{ns}$ \\
\hline \multicolumn{4}{|l|}{ Symptoms at entry to study: } \\
\hline Epigastric pain & $59(87 \%)$ & $45(68 \%)$ & $\mathrm{ns}$ \\
\hline Heartburn & $37(54 \%)$ & $23(35 \%)$ & ns \\
\hline Hacmorrhage & $19(28 \%)$ & $22(33 \%)$ & ns \\
\hline
\end{tabular}

NSAID $=$ Non-steroidal anti-inflammatory drugs differed between the groups: in the sucralfate group $47 \%$ were smokers, compared with $68 \%$ in the cimetidine group $(\mathrm{p}<0 \cdot 05)$.

\section{HEALING RATE}

Ulcer size significantly influenced the healing rate. In the sucralfate treated group healing rate for ulcers smaller than $6 \mathrm{~mm}$ was $73 \%$ and for ulcers larger than $6 \mathrm{~mm}$ healing rate was $51 \%$ at four weeks treatment $(p>0 \cdot 05)$. Corresponding figures in the cimetidine group were $85 \%$ and $53 \%$ $(\mathrm{p}<0 \cdot 01)$.

After eight weeks of treatment the small ulcers in the sucralfate group were healed in $92 \%$ and in the cimetidine group in $95 \%$. The corresponding figures for the larger ulcers were $96 \%$ and $93 \%$ respectively. The ulcer size did not significantly affect ulcer healing after eight weeks of treatment neither in the sucralfate nor in the cimetidine group. As healing rate was significantly affected by ulcer size in the cimetidine group after four weeks of treatment the difference in ulcer size between the treatment groups was taken into consideration when calculating the healing rates after four weeks, using Mantel's test. As will be seen from Table 4 the adjusted healing rates at four weeks is $61 \%$ for sucralfate and $69 \%$ for cimetidine. The cumulative healing rates after eight weeks were $94 \%$ for both the sucralfate group and the cimetidine treated group. After 12 weeks, the healing rates for sucralfate were $98 \%$ and for cimetidine $94 \%$, Table 4 and Figure 1 . Smoking did not have any significant correlation to ulcer healing in either of the groups after four, eight or 12 weeks of treatment.

The $95 \%$ confidence intervals for the difference in healing rates are also shown in Table 4 . The figures are calculated with respect to sucralfate, which means that after 12 weeks of treatment the healing efficacy of sucralfate might be at most $11 \%$ better or $2 \%$ worse than that of cimetidine.

\section{SYMPTOM RELIEF AND ANTACID INTAKE}

Of the 134 patients who completed the study, 64 in the sucralfate and 63 in the cimetidine group kept a proper record of their symptoms and antacid intake during the study. Epigastric pain, heartburn and antacid intake were compared between the groups every seventh day during the first eight weeks of

Table 3 Estimated ulcer size in 134 gastric ulcer patients treated with sucralfate $(1 \mathrm{~g}$ qid) or cimetidine (400 mg bd)

\begin{tabular}{|c|c|c|c|c|c|c|c|c|c|c|c|c|c|}
\hline Ulcer size $(\mathrm{mm})$ & 3 & 4 & 5 & 6 & 7 & 8 & 9 & $10-14$ & $15-19$ & $20-24$ & $25-29$ & $30-34$ & $>40$ \\
\hline Sucralfate treated patients & & & & & & & & & & & & & \\
\hline (n) & 8 & 18 & 1 & 11 & 4 & 5 & () & 11 & 3 & 5 & () & 1 & 0 \\
\hline Cimetidine treated patients & & & & & & & & & & & & & \\
\hline (n) & 5 & 2 & 7 & 5 & 4 & 3 & 1 & 16 & 12 & 3 & 1 & 4 & 2 \\
\hline
\end{tabular}


Table 4 Cumulative healing rates in 134 gastric ulcer patients treated with sucralfate (1 g qid) or cimetidine (400 mg bd)

\begin{tabular}{|c|c|c|c|}
\hline & Sucralfate & Cimetidine & $\begin{array}{l}\text { Confidence interval } \\
\text { for the difference } \\
\text { in healing rates }\end{array}$ \\
\hline No & 68 & 66 & \\
\hline Healing rate week 4 & $63 \%$ & $62 \% \mathrm{~ns}$ & \\
\hline $\begin{array}{l}\text { Healing rate week } 4: \\
\text { figures adjusted for } \\
\text { the difference in } \\
\text { ulcer size between } \\
\text { the treatment }\end{array}$ & & & \\
\hline groups & $61 \%$ & $69 \%$ ns & $(-23 \%, 9 \%)$ \\
\hline Healing rate week 8 & $94 \%$ & $94 \%$ ns & $(-8 \%, 8 \%)$ \\
\hline Healing rate week 12 & $298 \%$ & $94 \%$ ns & $(-2 \%, 11 \%)$ \\
\hline
\end{tabular}

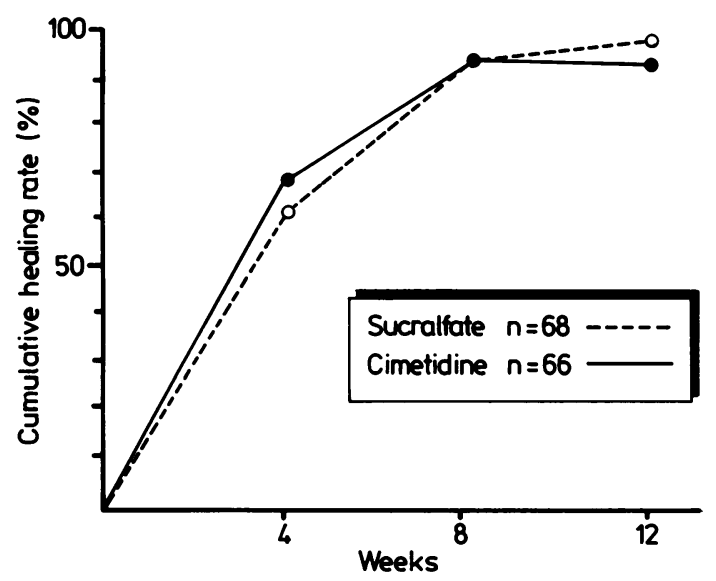

Fig. 1 Cumulative healing rate in 134 gastric ulcer patients treated with sucralfate (1 g qid) or cimetidine (400 $\mathrm{mg}$ bd). Sucralfate was administered to 68 patients and 66 patients were treated with cimetidine.

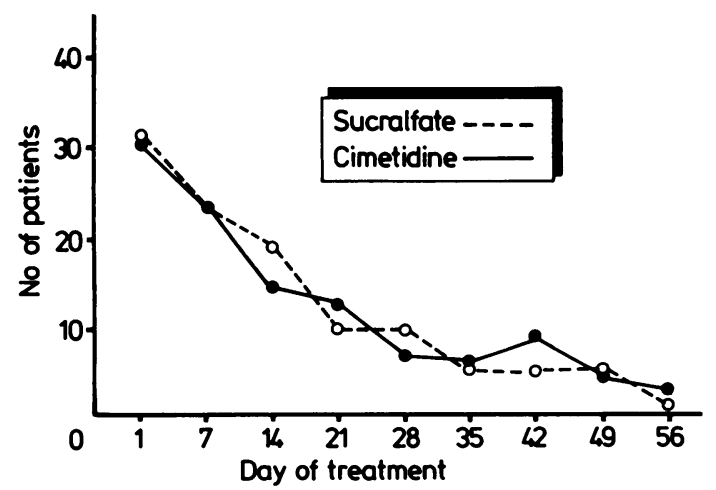

treatment, using Fisher's exact test. After eight weeks, only five patients were still under treatment. The number of patients complaining of diurnal or nocturnal epigastric pain is shown in Figure 2. There was a rapid fall in patients complaints of diurnal epigastric pain in both treatment groups. No significant difference between the groups was noted during the study.

As shown in Figure 2, patients with nocturnal epigastric pain were few and it is not possible to estimate the effect of the treatment on this symptom in this material.

The number of patients taking antacid tablets is shown in Figure 3. On the twenty first day of treatment, seven patients in the sucralfate group and 17 patients in the cimetidine group used antacid tablets $(p<0.05)$. The antacid intake decreased during the study and the curves approximately follow the curves for diurnal epigastric pain.

\section{LABORATORY FIN DINGS}

Statistically significant changes in laboratory values were not observed. Serum phosphate was monitored in 54 patients ( 29 on sucralfate treatment) and was not found to change during the treatment.

UNWANTED EFFECTS

The unwanted effects registered are shown in Table 5. No serious reaction was observed and no patient was withdrawn from the study because of side effects.

\section{Discussion}

Mucosal lesions in the upper gastrointestinal tract are believed to be due to an imbalance between mechanisms maintaining the integrity of the mucosa

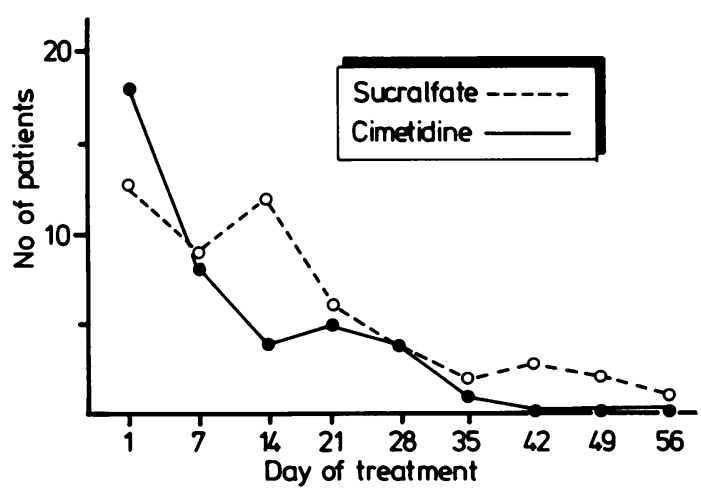

Fig. 2 Gastric ulcer patients complaining of epigastric pain during treatment with sucralfate ( $1 \mathrm{~g}$ qid) or cimetidine (400 mg bd). Figures are calculated from diary cards from 64 patients in sucralfate and 63 patients in cimetidine treated group. After 28 days of treatment, only 25 patients in each group were still under treatment. The number of patients with diurnal epigastric pain is shown in the left hand diagram and the number with nocturnal epigastric pain in the right hand diagram. 


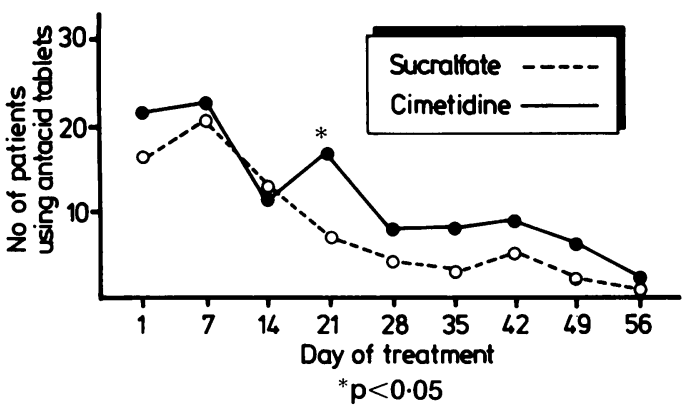

Fig. 3 Number of patients taking antacid tablets among 127 gastric ulcer patients treated with sucralfate (1 g qid) or cimetidine (400 $\mathrm{mg}$ bd). Initially, sucralfate was administered to 64 and cimetidine to 63 patients. After 28 days of treatment, only 25 patients in each group were still being treated.

Table 5 Unwanted effects recorded among 127 gastric ulcer patients during treatment with sucralfate $1 \mathrm{~g}$ qid) or cimetidine ( $400 \mathrm{mg}$ bd)

\begin{tabular}{lcc}
\hline & Sucralfate & Cimetidine \\
\hline No & 64 patients & 63 patients \\
Tiredness & 6 & 5 \\
Constipation & 2 & 4 \\
Dizziness & 0 & 2 \\
Nausea & 2 & 4 \\
Diarrhoca & 3 & 2 \\
Dry mouth & 1 & 3 \\
Meteorism & 1 & 5 \\
Headache & 3 & 1 \\
Other non-specific symptoms & 4 & 11 \\
\hline
\end{tabular}

and aggressive factors such as acid, pepsin, and bile salts. Reduction of intraluminal acidity has until recently been a primary aim of the treatment of peptic ulcer disease. Antacids, anticholinergics and $\mathrm{H}_{2}$-receptor antagonists are all effective in the treatment of duodenal ulcer. ${ }^{11-14}$ In the treatment of gastric ulcer, however, antacids or anticholinergics have not given convincing results as regards ulcer healing or symptom relief. ${ }^{1}$

Cimetidine, the first clinically used $\mathrm{H}_{2}$-receptor antagonist, has only in a few controlled studies given significantly better results than placebo in the treatment of gastric ulcer. ${ }^{2} 3$ Gastric ulcer patients have not been shown to have an increased acid secretion capacity. ${ }^{15}$ Thus, acid is not the only and perhaps not even the most important factor in gastric ulcer disease. Therefore recent research has focused on changes in the mucosal defence mechanisms.

The mucosal epithelium is protected from damage by mucus release, bicarbonate secretion, epithelial cell renewal from the deep mucosal cell proliferative zone, mucosal blood flow, intact cellular membranes and synthesis and release of prostaglandins. ${ }^{16}$ Cytoprotection has been defined as the ability of drugs to protect the gastric mucosa from necrotic damage by a variety of aggressive agents like alcohol, boiling water, acid, and overdistension ${ }^{16-18}$

Sucralfate has long been thought to heal ulcers by forming a protective barrier over eroded mucosa. This barrier is impermeable to acid, binds bile salts and inhibits pepsin activity. ${ }^{19}$ Recent investigations have shown that sucralfate also possesses cytoprotective properties, probably via stimulation of the local synthesis and release of prostaglandins. Mucosal blood flow, epithelial cell renewal and the formation of mucus is thereby enhanced. ${ }^{520}$ This, together with the absence of known interactions, extremely low toxicity and side effects ${ }^{21}$ makes this drug highly interesting in the treatment of gastric ulcer.

Sucralfate and cimetidine have earlier only in a few studies been compared in the treatment of gastric ulcer. The healing rates for both drugs have been reported beween $40-60 \%$ after four and $75-85 \%$ after eight weeks of treatment. ${ }^{722} 23$ Only Marks $^{6}$ has treated patients for 12 weeks and he reported $83 \%$ healing rate for sucralfate and $89 \%$ for cimetidine. In all the above cited studies sucralfate has been administered in a dose of $1 \mathrm{~g}$ qid and cimetidine in a dose of $200+200+200+400 \mathrm{mg}$ with exception for Martins study ${ }^{23}$ in which the patients received cimetidine $300 \mathrm{mg}$ qid. Significant differences in healing rate or symptomatic relief between the treatment groups could not be demonstrated in any of these studies, corresponding well to our present study. The healing rates in our study were in both groups slightly higher than in the above cited studies both after four, eight and 12 weeks of treatment. This may be because of differences in the ulcer population or the ulcer size.

When presenting the results of an ulcer healing study comparing different drug treatments, most authors declare the drugs equally effective if there is no significant difference beween the drugs. It is often forgotten that, even if the $p$ value is greater than 0.05 , there is a risk of falsely accepting two treatments as equally effective although the true difference in healing rates may be large. ${ }^{24}{ }^{25} \mathrm{~A}$ more reliable comparison of efficacy is the $95 \%$ confidence interval for the difference in healing rates between the drugs. ${ }^{10}$ This means that the probability that the true difference between healing rates is not within this interval is less than $5 \%$.

It is not unusual that a single comparison among a large number of statistical calculations on the same material may show a significant difference. This can be referred to random and therefore the isolated significant difference in patients taking antacid 
tablets on day 21 cannot be regarded as clinically relevant. The overall intake of antacid was very low and did not reach the acid neutralising capacity that is necessary for ulcer healing. ${ }^{26}$ Although antacid compounds give relief of acute symptoms, we find it preferable to minimise antacid intake in gastric ulcer therapy when other drugs like sucralfate or cimetidine are used. Antacids have unwanted effects and may also interfere with the bioavailability of other drugs, including cimetidine. ${ }^{27}$ Large amounts of antacid taken together with sucralfate might also interfere with the sucralfate-protein binding capacity. ${ }^{21}$ The unwanted effects recorded in our study are similar to those previously reported ${ }^{2128}$ and no serious adverse reactions were noted.

Sucralfate and cimetidine are both effective in the short term treatment of gastric ulcer. The $95 \%$ confidence interval for the difference in ulcer healing efficacy between sucralfate and cimetidine ranges from $+11 \%$ to $-2 \%$ - that is, the healing efficacy of sucralfate is at most $11 \%$ better or $2 \%$ worse than that of cimetidine.

We wish to thank Farmos Group AB and SK\&F CO for the supply of drugs during the study. We also thank the endoscopy assistants at our hospitals, who have helped us with both clinical and administrative work, Anders Odén, PhD who has done the statistical calculations and Mrs Maj-Lis Fröjd, at the Surgical Department in Trollhättan, who typed the manuscript.

\section{References}

1 Lewis JH. Treatment of GU. Arch Intern Med 1983; 143: $264-74$.

2 Isenberg J, Elashoff JD, Sandersfield M et al. Double blind comparison of cimetidine and low dose antacid versus placebo in the healing of benign GU. [Abstract]. Gastroenterology 1982; 82: 1090.

3 Akdamar K, Dyck W, Englert E et al. Cimetidine versus placebo in the treatment of benign $\mathrm{GU}$. [Abstract]. Gastroenterology 1981; 80: 1098.

4 Nagashima $R$. Development and characteristics of sucralfate. J Clin Gastroenterol 1981; 3: suppl 2: 103-10.

5 Tarnawski A, Hollander D, Krause WJ, Zipser RD, Gergely $H$. Effect of sucralfate on normal gastric mucosa. Histologic ultratractional and functional assessment. [Abstract]. Gastroenterology 1983; 84: 1331.

6 Marks IN, Wright JP, Denyer M, Garisch JAM, Lucke W. Comparison of sucralfate with cimetidine in the short term treatment of chronic peptic ulcers. $S A f r$ Med J 1980; 57: 567-73.

7 Lahtinen J, Aukee S, Miettinen P, Poikolainen E, Pähönen M, Sandström R. Sucralfate and cimetidine for GU. Scand J Gastroenterol 18 suppl 33: 49-51.

8 Odén A, Wedel H. Arguments for Fisher's permutations test. Ann Statist 1975; 3: 518-20.
9 Mantel N. Chi square tests with one degree of freedom: Extension of the Mantel-Haenszel procedure. J Am Statist Assoc 1963; 58: 690-700.

10 Elashoff J. Statistical considerations in Drug Trials of Peptic Ulcer. J Clin Gastroenterol 1981; 3: 135-40.

11 Berstad A, Ryding A, Aadland E, Kolstad B, Frislid $\mathrm{K}$, Aaseth J. Controlled clinical trial of duodenal ulcer healing with antacid tablets. Scand J Gastroenterol 1982; 17: 953-9.

12 Ström M, Gotthard R, Bodemar G, Walan A. Antacid/ Anticholinergic, cimetidine and placebo in treatment of active peptic ulcers. Scand J Gastroenterol 1981; 16: 593-602.

13 Wormsley KG. Short term treatment of duodenal ulceration. Cimetidine in the 80s. Edinburgh: Churchill Livingstone 1981: 3-8.

14 Freston JW. Cimetidine. Ann Intern Med 1982; 97: 573-80.

15 Richards CT. Gastric ulcer. In: Sleisinger MH, Fortran SS eds. Gastrointestinal disease. Philadelphia: Saunders, 1978: chap 51.

16 Tarnawski A. Cytoprotection - A future direction in prevention and treatment of GI mucosal injury. Curr Concepts Gastroenterol 1984; 9: 5-12.

17 Marti-Bonmati E, Alino SF, Lloris JM et al. Effects of cimetidine, atropine and prostaglandin $E_{2}$ on rat mucosal erosions produced by intragastric distension. Eur J Pharmacol 1980; 68: 49-53.

18 Tarnawski A. Cytoprotection. A new fashion or real progress. Pol Arch Med Wewn 1980; 64: 97-104.

19 Samloff IM. Inhibition of peptic agression by sucralfate. A view from the ulcer crater. Scand J Gastroenterology 1983; 18: 7-11.

20 Hollander D, Tarnawski A, Gergely H, Zipser RD. Sucralfate protection of the gastric mucosa against ethanol induced injury. A prostaglandin mediated process? Scand J Gastroenterol 1984; 19: 97-102.

21 Fisher RS. Sucralfate: A review of drug tolerance and safety. J Clin Gastroenterol 1981; 3 suppl 2: 181-4.

22 Pop P, Nikkels RE, Thys O, Dorrestein GCM. Comparison of sucralfate and cimetidine in the treatment of duodenal and gastric ulcers. A multicenter study. Scand J Gastroenterol 1983; 18: 43-7.

23 Martin F, Farley A, Gagnon M, Poitras P, Bensemana D. Short term treatment with sucralfate or cimetidine in gastric ulcer. Scand J Gastroenterol 1983; 18: 37-42.

24 Peterson L, Elashoff J. Placebos in clinical trials of duodenal ulcer. The end of an era. Gastroenterology 1980; 79: 585-8.

25 Freiman JA, Chalmers TC, Smith $\mathrm{H}$ et al. The importance of beta, the type II error and sample size in the design and interpretation of the randomized control trial. N Engl J Med 1978; 299: 690-4.

26 Walan A. Antacids and anticholinergica in the treatment of duodenal ulcer. Clin Gastroenterol 1984; 13: 473-99.

27 William M, Steinberg MD, James H, Lewis MD, Debra M, Katz BS. Antacids inhibit absorption of cimetidine. N Engl J Med 1982; 307: 400-3.

28 Freston JW. Cimetidine, adverse reactions and patterns of use. Ann Intern Med 1982; 97: 728-34. 